\title{
Benefits and Challenges of Adopting Google Classroom in Malaysian University: Educators' Perspectives
}

\author{
Maheran Zakaria, Faculty of Accountancy, Universiti Teknologi MARA, Cawangan Kelantan, Malaysia. \\ Junaidah Hanim Ahmad, Faculty of Accountancy, Universiti Teknologi MARA, Cawangan Kelantan, \\ Malaysia. \\ Rosliza Bahari, Faculty of Accountancy, Universiti Teknologi MARA, Cawangan Kelantan, Malaysia. \\ Siti Jeslyn Hasan, Faculty of Accountancy, Universiti Teknologi MARA, Cawangan Kelantan, Malaysia. \\ Salwa Zolkaflil, Accounting Research Institute, Universiti Teknologi MARA, Shah Alam, Malaysia. \\ salwazolkaflil@gmail.com
}

\begin{abstract}
The COVID 19 pandemic has led us to use Google classroom in the teaching and learning process worldwide since it is easily accessible at any time to an unlimited number of learners. Despite many benefits claimed, previous literature also cautioned on challenges associated with this web-based platform, especially from the learners' point of view. Intrigued by these issues, the objective of this study is to explore the benefits and challenges in the adoption of Google classroom from the educators' perspective by referring to the Technology Acceptance Model (TAM). Thus, a phenomenography study had been employed, involving forty accounting lecturers from one of the universities in Malaysia. Data were gathered through an open-ended questionnaire and analysed qualitatively using NVivo 14 . The results indicated that five emergent themes derived from the benefits namely outcome and process satisfaction, ease of use, paperless and usefulness. Meanwhile, four themes were elicited for challenges; attitude, student engagement, effort expectancy and facilitating condition. The benefits indicate the vast potential of online learning, while the challenges provide insight into what needs to be done. Hence, the optimum use of this web-based platform will enhance quality education and promote lifelong learning opportunities for both educators and learners.
\end{abstract}

Keywords: Google Classroom, Higher Learning Institutions, Educators

Received: $10.11 .2020 \quad$ Accepted: 03.12.2020 $\quad$ Published: 06.01.2021

\section{INTRODUCTION}

E-learning has now replaced the traditional classroom method with online delivery using the internet (Nguyen, 2015) and brings transformative innovation for the higher education (Abed, 2019; Garrison \& Kanuka, 2004). Educators need to find ways to optimally use the available platforms to ensure that the learning process is not disrupted. One of the popular online learning platforms is Google Classroom, which has been used globally. Being aware of the importance of technology in education, the Malaysian Ministry of Education has collaborated with tech giants such as Google, Microsoft and Apple to revamp its year-old digital learning platform and enhance the e-learning platform (Xiung, 2020).

As of April 2020, Malaysia garnered the highest search for Google Classroom globally, which indirectly indicated the spike in the interest among the Malaysians towards Google Classroom (Hairom, 2020). Among the reasons of why the Malaysian educators have a high preference for using this web-based educational platform are its accessibility, user friendly, usefulness and free usage. However, the usage of Google Classroom has been a challenge especially those in rural areas due to weak internet coverage and high maintenance cost. Despite these adversities, Google Classroom has huge potential and is expected to continue to be a vital part of the education landscape (Bhuasiri et al., 2012). To some educators, this webbased platform is becoming ubiquitous, but to others, it aggravates pressure and therefore they resist accepting the new changes in their lives. These issues have sparked the interest of many studies to explore the benefits and challenges of Google Classroom (Blackmont, 2017; Heggart \& Yoo, 2018; Basheer, 2018). Many studies have focused on learners' perspectives, yet limited attention was given towards the educators.

Thus, this study aims to explore the benefits and challenges in adopting Google Classroom from the perspective of accounting educators in one of the higher learning institutions in Malaysia. This higher learning institution has shifted to e-learning mode since April 2020 (Abu Karim, 2020), making it interesting to explore the adoption of Google Classroom as their e-learning platform. The next section will review past literature concerning e-learning and Google Classroom. This will then be followed by the 
methodology section. Next, there will be sections on results and discussion, and conclusion. The paper will also highlight the limitations of the study which will lead to the potential for future research.

\section{LITERATURE REVIEW}

\section{Online learning, e-learning, and web-based learning}

The advent of technology has enabled the use of online learning in schools as well as higher learning institutions. There is growing interest in the subject, especially on the effectiveness of the platform in teaching and learning process. While some are fascinated as they believe that the use of such tools will revolutionise higher education by increasing learner engagement, democratising access and enhancing learning (Galway et al., 2014; Hilton, 2009, Siemens \& Tittenberger, 2009), others are more skeptical as they recommended limited use of social media tools in the classroom because of limited impact upon learner learning and its potential for distraction (Selwyn, 2007). Some are reluctant to change the way of teaching that they have been accustomed to.

Kuh et al. (2001) as mentioned by Harjanto and Sumarni (2019) pointed out that technology has been proven to enhance students' active participation and learning outcomes. The students are motivated and excited to participate in lessons that integrate with technology (Ali et al., 2012). The excitement encourages the students to pay full attention and perform well in their studies. However, there are studies which concern the negative implication of technology usage in the learning process towards student's performance. Simply implementing the use of new technology without proper planning and training may not bring any good to the students' outcomes or engagement, not because of systems, but due to the lack of critical thought about how best to use these tools (Chen \& Denoyelles, 2013). Therefore, there is a need for educators and students to explore the online learning platform and to fully utilise the features provided by the online learning platform.

\section{Google Classroom}

Google Classroom is one of the popular e-learning platforms that has rapidly diffused into the education system worldwide. Google Classroom is a free educational web service that aims to simplify creating, distributing, and grading assignments in a paperless way. It offers a multitude of pedagogical and technological features and is accessible to anyone with internet access. Like the physical classroom, educator can create a class for a course and invite other educators and learners to join the class. Upon joining, they would all become members or citizens of the virtual class and can have immediate access and be connected.

An appealing factor for Google Classroom is it integrates the many features of Google such as Google Drive for assignment creation and distribution, Google Docs, Sheets and Slides for writing, Gmail for communication, and Google Calendar for scheduling. Apart from its impressive educational and digital features, it is offered for free and can be used by any institution, specifically those with limited resources to set up their own Learning Management System.

This has been elicited by several studies that explored the benefits and challenges experienced by higher institutions' learners (Blackmon, 2017; Beaumont, 2018; Gilbert, 2015; Heggart \& Yoo, 2018; Iftikar, 2016). Amongst the benefits of Google Classroom highlighted in previous research are paperless communication, ease of access, systematic class management, fostering communication within a community, organising folders, sharing information, posting assignments and viewing all posted works in real-time (Beaumont, 2018). However, it is also worthy to note that learners also experience various challenges in adopting Google classroom. Among the challenges are the late response from educator, unreliable connection, no in-person connection, and lack of support (Basher, 2017; Azhar \& Iqbal, 2018; Sharanee et al., 2016). One of the theories used in understanding the implementation of e-learning by looking into its benefits and challenges is the Technology Acceptance Model.

Technology Acceptance Model. Technology Acceptance Model (TAM) was first introduced by Fred Davis in 1986 which was applied mostly in explaining users' acceptance of new technologies or information systems (Lai, 2017). According to the model, the actual use of a new technology depends on the attitude towards technology. Two specific beliefs namely Perceived Usefulness (PU) and Perceived Ease of Use (PEU) are the factors influencing the attitude.

Perceived Usefulness is defined as the subjective likelihood on the use of a certain system (for example, Google Classroom). Perceived usefulness in e-learning has been demonstrated as useful in providing resourceful information at the right time and place for the support and improvement of students' university life (Chen \& Tseng, 2012). In this study, perceived usefulness is referred to as the benefits of adopting Google Classroom as e-learning platform. Among the benefits of adopting Google Classroom are accessible at any time without restriction (Heggart \& Yoo, 2018), features that allow the concept of sharing 
materials (Beaumont, 2018), and users are able to manage and focus completely on tasks without distractions as in physical classes according to their capability (Gilbert, 2015).

Perceived Ease of Use refers to the degree of user's expectation that the system is free of effort (Davis, 1989). It concerns with user's motivation in using the technology, such as its interface and processes involved. Perceived ease of use refers to the technology or system self-efficacy and facilitating conditions (Venkatesh, 2000). Self-efficacy is crucial to ensure that the users can enjoy the features offered by the technology. Therefore, it is important to provide training before introducing the technology to the users. Beginners find it difficult in familiarizing themselves with Google Classroom interface. Therefore, extra time is required for the learners to explore and get familiar with Google Classroom interface (Iftakar, 2016).

TAM has been used widely in e-learning acceptance research (Cheon, Lee, Crooks, \& Song, 2012; Lee, 2010). Therefore, the study refers to TAM (Davis, 1989) in understanding the benefits and challenges faced by educators in adopting Google Classroom in their teaching and learning process. The following section discusses the benefits and challenges of adopting Google Classroom as their e-learning platform.

\section{Benefits and Challenges of Google Classroom}

Google Classroom has been adopted as a web-based platform since 2015 as it provides a good interactive platform for the educators and the learners. Various prior research was conducted on the benefits and challenges of Google Classroom as the web-based platform (Alim et al., 2019; Beaumont, 2018; Blackmon, 2017; Gilbert, 2015; Harjanto \& Sumarni, 2019; Heggart \& Yoo, 2018; Iftakar, 2016; Zakaria et al., 2020).

Benefits of Google Classroom. Gilbert (2015) did a study on learners who enrolled in an online American History course at High School in the US. The study found that the usage of Google Classroom benefits the learning process, especially the students as it allowed them to work at their own pace according to their own educational needs. Learners were able to manage and focus completely on tasks without distractions as in physical classes according to their capability.

Google Classroom also allows real-time questions and answers as well as being able to schedule the posts earlier. Since it is a web-based learning platform, Google Classroom is accessible at any time without restriction (Heggart \& Yoo, 2018). Its accessibility has made the learners at the tertiary level of an Australian higher institution able to enjoy their learning process more as it allows them to express their ideas comfortably (Heggart \& Yoo, 2018). Eventually, these would lead to an increase in the quality of learning as the learners are confident that their ideas were seen within a web-based community.

Google Classroom also has a feature that allows the concept of sharing materials among the users. Beaumont (2018) conducted a study in the United Kingdom (UK) which found that the concept of sharing materials in Google Classroom would nurture a sense of collaboration among the class community. This web-based platform could also be easily accessed and navigated through laptops and smartphones, and it provides collaborative work opportunities with other Google features namely documents, slides, and calendars for free.

In Malaysia, a study conducted by Zakaria et al. (2020) on higher institution's learners found that Google Classroom is very helpful for the facilitation of assignments and allows systematic class management. The class management has become more systematic as it allows the material to be organised according to the codes, subjects, and classrooms. Therefore, the learners found it easier to refer to the materials since it is well organised in Google Classroom.

Despite enjoying the bountiful benefits from Google Classroom adoption, learners also experience various challenges in adopting Google Classroom. This has been elicited by several previous studies.

\section{Challenges of Google Classroom}

Learners, especially beginners, find difficulties in familiarizing themselves with Google Classroom interface. Some of them are not aware of the features offered by the web-based platform that would benefit them. Therefore, extra time is required for the learners to explore and get familiar with Google Classroom interface (Iftakar, 2016).

Blackmon (2017) and Zakaria et al. (2020) mentioned that the learners found it challenging due to a lack of in-person interaction between the class communities. Some learners felt left out without an educator's guidance, making it difficult to comprehend, especially at the beginning of the course. The utmost challenge encountered by the learners was late or non-response by the educator. This leaves them in a dilemma as to whether their work has met the expectation. This is because Google Classroom had nobuilt-in features to analyse an individual learner's contribution or a rudimentary analysis on the kinds of the contribution made by each of them.

Another challenge faced by the learners is accessibility problem concerning the messages posted on the 'stream' (a feature on Google classroom) (Zakaria et al., 2020). This is because the latest announcements, messages, comments, and discussions always appear on the top. Older messages would 
then move further down the stream as new messages are posted. The learners also face several challenges such as all comments and messages are automatically arranged; thus, it can be quite difficult for the learners to track certain comments later on (Beaumont, 2018).

To some users, Google Classroom aggravates financial pressures as there is a web-based platform which requires a strong internet connection and good devices for them to enjoy their e-learning process (Iftakar, 2016; Alim et al., 2019; Harjanto \& Sumarni, 2019; Zakaria et al., 2020) This has been a challenge because there are learners who cannot afford to purchase a smartphone or laptop due to their financial standing. Besides, the learners also find it difficult for them to enjoy their e-learning process due to limited mobile data plan especially during the online discussion (Alim et al., 2019; Harjanto \& Sumarni, 2019). Having an unreliable internet connection at home is also one of the challenges faced in completing tasks within the constraint of school hours. Thus, these limitations restrict their accessibility to Google Classroom and their ability to submit their assignments on time.

As most previous literature on the benefits and challenges of Google Classroom was conducted on learners, this study intends to bridge the gap by researching to understand the educators' perspectives. It would be interesting to note whether the educators perceive the same benefits and challenges as the learners concerning the use of Google Classroom.

\section{METHODS}

A phenomenology study had been conducted to explore the benefits and challenges experienced by 40 accounting lecturers from one of Malaysian Public Higher Learning Institutions in using Google Classroom. However, this study is just a preliminary study to understand the adoption of Google Classroom. In line with the phenomenology concept by Marton (1986), this study aims to explore the experience of the educator, in the adoption of Google Classroom. The lecturers were invited to express what they believe as the benefits and challenges of using Google Classroom using an open-ended questionnaire that was posted using the Whatsapp application, which is in line with the recommendation by DeCoito (2018).

They were informed that the participation was voluntary which means that they could ignore it if they do not want to participate. The respondents were asked to relate their thinking on the benefits and challenges experienced by them in adopting Google classroom. They were also assured that their responses would be treated anonymously and confidentially. The instruments consisted of the following questions: Based on your experience, what are the benefits of a web-based Google Classroom? Based on your experience, what are the challenges of a web-based Google Classroom?

\section{Data Analysis}

The study used Nvivo (Version 14) to identify patterns, connections, and emergent themes of the narrative description of the participant's experiences. The codes produced by the software were further organised with the purpose to look for similarities and differences among the collected data. Functions, actions explanations and contexts were then labeled under appropriate categories, in accordance to Neuman (2007). The process of analysis was later moved from coding to interpretation before concluding.

The results produced by Nvivo were later triangulated with other main sources of evidence such as informal conversations, documentation, and direct observation before a report in narrative statements. The emerging themes derived from the findings were then merged with themes supported by TAM. Various sources of evidence were used to ascertain the accuracy, authenticity, and validity of data. The convergence of multiple sources of evidence further enriched the understanding of the benefits and challenges that would lead to a more convincing and accurate explanation about the benefits and challenges of adopting Google Classroom as perceived by the educators. The data were then triangulated with other evidence to ensure the reliability and consistency of data apart from delving deeper into understanding and interpretation.

\section{RESULTS}

Code, Sub-theme, and Theme. The study aims to explore the benefits and challenges in adopting Google Classroom from the perspective of accounting educators. Five themes with 13 codes were revealed under the benefits, while the challenges generated four themes with 12 codes.

The benefits and challenges of Google Classroom experienced by educators are discussed further in the following sub-section. The participant is represented by educator (E) followed by a reference number. 


\section{Benefits of Google Classroom (Theme)}

\section{Sub-theme 1: Outcome Satisfaction.}

The most prominent benefit that emerged from the educators' response in using Google Classroom was outcome satisfaction. Almost every respondent was satisfied with its outcomes.

"Sharing lecture materials with my students are simple; thus, making teaching and learning easier...." E4

"I share videos, educational and motivational stories with my students using GC, they can give a response at any time...." E5

"GC is used to store teaching materials, little space is required; thus, my students prefer using it..." E26

"I used GC to communicate, give instructions to my students regarding their project requirements, assignments and tests..." E11

"Preparing notes and exercises, and uploading it to Google Classroom is an easy process...."

E12

"I use GC together with other Google applications such as Google Meet to encourage my students to participate and to enhance their learning experience...." E13

"I use GC for distribution of tutorial documents, lecture notes...." E17

\section{Sub-theme 2: Process satisfaction.}

Most respondents also indicated that they were satisfied with Google Classroom as a platform for giving out tests and assignments extensively.

"I give assignments and instructions using GC, it is very convenient once I got a hang of it...." E1

"I used GC to save teaching materials, make announcements and memos regarding assignments and tests...." E6

"I used GC to share materials, assignments and tests. It is easy and more organized..." E7

"I used GC to give instructions to my students regarding their projects, assignments and tests...." E11

"It is my most preferred application for tests and quizzes...." E17

\section{Sub-theme 3: Ease of use.}

The third benefit that can be observed from the responses given by the educators was the ease of use. Google Classroom was not uncommon since educators in this institution were required to use Google Applications in one form or another, for example, Google Mail, Drive and Google Documents.

"I am good at applying technology in my teaching, it is easy to learn new applications...." E3

"Google applications are familiar since I use Gmail and Chrome. It took me a short period to learn to use GC...." E19

Google Classroom can be accessed from all computers, mobile phones and tablets. Educators also found it highly manageable as they can add as many codes or classrooms as they wanted.

"Not every student has access to a laptop or a computer...but they everyone has smartphone...." E7

"I have four classes and three codes to teach this semester, all are converted to virtual classes without much difficulty...." E19

"It does not need a lot of expenses, low cost, little data is required...." E12

\section{Sub-theme 4: Usefulness.}

Another positive feature of Google Classroom that can be extracted from one of the responses was usefulness. Usefulness means that the educator is able to apply different instructions for each of the classrooms. Each class can be given different tasks and guidance. This is useful for facilitating educators in managing different classes.

"Different groups within the same course can be assigned with different tasks without any

difficulty...." E30

\section{Sub-theme 5: Paperless}

The last sub-theme of Google Classroom's benefit was that it helps to reduce the usage of papers; thus, reducing cost and being friendly to the environment. 
"I do not need to print students' work and tests because marking and grading can be done online...." E29

"I can easily return students' work, graded with comments, online through GC..." E21

\section{Challenges of Google Classroom (Theme)}

\section{Sub-theme 1: Student's engagement.}

When using Google Classroom, participants addressed the difficulty they faced in encouraging the students to participate, for example in online discussions.

"I had to be more creative, choose the right words and approach to ensure students become more participative...." E2

"When I called out a student to respond, it was just like talking to the brick wall...." E3

"It was frustrated when nobody responds to your question...." E7

As Google Classroom is designed with the attributes of a virtual classroom, participants believed that they had less connection with students as opposed to a traditional classroom setting.

"It is more exciting to interact face-to-face with students...." E32

"I had to build a bond with my students virtually...." E5

"I wish to have closer contacts and interact face-to-face with my students ...." E5

"Sometimes my students asked for a virtual meeting so they could see lecturer's and friends' faces...." E7

"Face-to-face presence had to be replaced with words...." E8

"In terms of communication with students, GC has its limitation...." E17

Participants also highlighted that they had to put more trust in students with regard to self-learning and online assessments via Google Classroom.

"I could not know whether my students read my notes or more importantly whether they understand the topic...." E2

"Lecturers are inclined to believe that students are more susceptible to cheat during online assessments...." E23

"I had to put more trust on my students when conducting the online assessments...." E35

A few participants were concerned about the level of their students' motivation and readiness to adopt Google Classroom in their learning.

"It is very challenging to ensure students' enthusiasm for learning is kept high all the time...." E2

"There are a few cases of students feeling lost...." E8

"Students' seemed to be less motivated to use GC as they were used to traditional classroom setting...." E13

"Not all students are ready to use online classrooms like GC...." E40

"Students are less motivated to study on their own without friends by their side...." E18

Another challenge expressed by the participants was the inability of Google Classroom to promote timely and easier communication between educators and learners.

"Students prefer to send a personal message to ask questions...." E12

"For instantaneous response, GC is less preferable...." E28

"WhatsApp and Telegram are more suitable to use when you are running out of time or want to connect to students instantly...." E16

\section{Sub-theme 2: Effort expectancy}

Participants mentioned that they had to allocate a huge chunk of their time to set up Google Classroom and familiarize themselves with the technical aspects of Google Classroom.

"I had to provide more time to convert my hard copy notes to digital copy so it can be uploaded to my GC...." E17

"This is something new to me, so I had to allocate more time to learn from the beginning...." E33

"I had to spend more time familiarizing myself with GC by doing trial and error...." E14

"More time needed to fully understand how GC works...." E31

When using Google Classroom as a platform for discussions and assessments, participants raised the following comments:

"I had to spend more time discussing questions with my students...." E33

"To prepare and grade online assignments are very time-consuming...." E24 


\section{Sub-theme 3: Attitude}

Attitude towards Google Classroom in its negative form appeared to be the biggest challenge to be battled by the participants.

"Honestly, I am not ready to use GC...." E1

"It feels like I was forced to adopt the online teaching...." E2

"It is harder to teach online when it involves calculations...." E24

"I miss the environment of teaching in a real classroom...." E15

"I doubted whether my online teaching could meet its objectives...." E27

"I am not IT savvy...." E8

Negative attitudes towards Google Classroom came in pair with the reluctance to switch from the traditional method to online teaching.

"I am more comfortable teaching in a real classroom...." E2

"It is something new to me...." E9

"I am too comfortable with the old style of teaching and standing in front of students...." E11

"My teaching style had to be changed 180 degrees to suit this new style of teaching...." E13

"For me as a lecturer, going to class with my heavy books and whiteboard markers is still my first choice...." E34

Many participants also emphasized their lack of knowledge and skills to adopt Google Classroom.

"I am still trying to familiarize myself with GC...." E21

"Using GC means you need to have IT skills in addition to your basic teaching skill ...." E22

"I had to read here and there, discussed with fellow lecturers and joined online classes to prepare myself with GC...." E6

"I am not prepared and do not know GC...." E10

"At first, I was struggling to use GC because I had never used it before...." E12

\section{Sub-theme 4: Facilitating condition}

One of the biggest challenges yet inevitable is the unstable internet connection encountered by the participants.

"It took hours to upload one simple material to the GC...." E21

"It is so hard to use GC when the internet speed was at a snail's pace...." E33

"The internet access was very poor and unstable...." E10

"I had to switch to a new service provider for better internet connection...." E11

"Using GC when the internet connection is poor can be very challenging...." E15

"GC needs to be supported with other mediums especially when the internet access is problematic...." E17

"Internet access is my greatest challenge...." E18

Even so, a superior internet connection was meaningless when some participants mentioned another challenge regarding the required tools that they need to run their Google Classroom.

"I had to purchase a new PC for my GC because I don't have one...."E 6

"I cannot use GC when I do not have basic equipment such as laptop, PC and internet subscription...."

\section{DISCUSSION AND CONCLUSIONS}

The web-based learning platforms such as Google Classroom has grown at a rapid pace, due to technological advancement. The findings of the study show that educators do believe in the usefulness of Google Classroom in their teaching and learning process, which are similar to Beaumont (2018), Blackmon (2017), Gilbert (2015), Heggart \& Yoo, (2018), and Iftikar (2016). Five sub-themes for benefits emerged from the responses namely outcome satisfaction, process satisfaction, ease of use, usefulness and paperless. Meanwhile, four sub-themes were derived from challenges namely student engagement, effort expectancy, facilitating condition and attitude. These sub-themes were aligned to elements as proposed by Technology Acceptance Model (TAM).

Google Classroom acted as an effective medium of communication with its students through the effortless sharing of teaching materials. The storage available is plentiful and integrated with other Google applications allowing more effective interactions (Gilbert, 2015; Heggart \& Yoo, 2018) and allow educators to schedule and manage tests or assignments online (Zakaria et al., 2020). This feature helps the learners to be able to submit their work faster while the receiving end can track and record their submission. It is 
also seen that less or no paper is required because teaching materials were shared in the digital format and student' assessments were performed online, which is environmentally friendly.

Another element under TAM is perceived ease of use. The ease of use of a technology is important as it will determine whether the users will enjoy or reluctant to use the technology. There are many devices available in the market which are compatible with Google Classroom application, making it highly accessible by the users. The educators also believed that it leads to systematic organization of their classrooms and subjects, which is in line with Gilbert (2015) and Heggart and Yoo (2018).

However, some of the educators find it challenging that reflects their unreadiness to adopt Google Classroom due to lack of self-efficacy and difficulty in handling the students virtually. The educators have a higher preference for face-to-face learning process due to difficulties to attract students to participation (Blackmon, 2017; Desai et al., 200; Singh et.al., 2020; Woldeab et al., 2020; Zakaria et al., 2020). Therefore, it requires extra effort to learn and familiarize with Google Classroom, which is supported by Azhar and Iqbal (2018). This is in tandem with the suggestion in a study by Sidhu et al. (2019) in which educators must have sufficient knowledge and understanding to confidently embrace ICT tools like Google classroom. This indirectly highlights that there is a lack of training provided to them in facilitating Google Classroom adoption.

Therefore, the university is encouraged to organise periodical training for the educators to help them be ready in using Google Classroom to help them change their "difficult to use mindset" into "ease to use mindset". It will also help them to be motivated in using Google Classroom. However, there is also an external factor identified which is facilitating condition. Having reliable internet connectivity is vital in using Google Classroom, either for a learner or an educator. A similar finding was reported in Islam and Ferdousi (2019), Zakaria et al. (2020) and Alim et al. (2019). A few educators also mentioned the need for a suitable device such as a laptop, personal computer, or tablet for them to use Google Classroom.

In a conclusion, this study found that educators are aware on the usefulness of Google Classroom as an effective e-learning process. However, due to the lack of knowledge and facilities (devices and internet connection), they find it challenging to conduct e-learning through Google Classroom as compared to a physical classroom. Therefore, the university needs to ensure that all educators are equipped with computer skill and online teaching skills, and provide the required facilities such as computers and internet connection.

This study's findings reveal both theoretical and practical implications. Theoretically, this study further supports the applicability of TAM in a developing country like Malaysia as it relates to Google Classroom as the web-based learning platform. Practically, the findings present insights on the effectiveness of Google Classroom and help in monitoring the readiness of the educators and students in adopting Google Classroom. The challenges derived in this study will benefit the university's top management and Ministry of Education in ensuring effective teaching and learning processes. The finding highlights that it is important to have well-trained educators and good facilities to produce effective teaching and learning processes.

However, this study is just a preliminary study to understand the adoption of Google Classroom. Since this study only focuses on a simple open-ended questionnaire on the educators' point of view, the findings are limited to the experiences of the respective educators. Future research may extend the study by conducting questionnaires and support the findings with interviews on the respective participants. It is also good to conduct a similar study in a different setting, such as in private universities, since they have different facilities as compared to public universities.

\section{REFERENCES}

Åkerlind, G. S. (2005). Variation and commonality in phenomenographic research methods. Higher education research \& development, 24(4), 321-334.

Alim, N., Linda, W., Gunawan, F. \& Md Saad, M. S. (2019). The effectiveness of Google Classroom as an instructional media: A case of State Islamic Institute of Kendari, Indonesia. Humanities \& Social Sciences Reviews, 7(2), 240-246.

Azhar, K. A., \& Iqbal, N. (2018). Effectiveness of Google classroom: Teachers' perceptions. Prizren Social Science Journal, 2(2), 52-66.

Beaumont, K. (2018). Google Classroom: An online learning environment to support blended learning. Compass: Journal of Learning and Teaching, 11(2).

Blackmon S. (2017). The stream's the thing: Google classroom and graduate education. http://er.educause.ed/articles/2017/8the-streams-the-thinf-google-classroom-and-graduateeducation. Access 11 September 2019. 
Chang, C., Yan, C., \& Tseng, J. (2012). Perceived convenience in an extended technology acceptance model: Mobile technology and English learning for college students. Australasian Journal of Educational Technology, 28(5).

Cheon, J., Lee, S., Crooks, S., \& Song, J. (2012). An investigation of mobile learning readiness in higher education based on the theory of planned behavior. Computers \& Education, 59(3), 1054-1064.

Chen, H., \& Tseng, H. (2012). Factors that influence acceptance of web-based e-learning systems for the inservice education of junior high school teachers in Taiwan. Evaluation and Program Planning, 35(3), 398-406.

Davis, F. D. (1989). Perceived usefulness, perceived ease of use, and user acceptance of information technology. MIS Quarterly, 13(3), 319-340.

DeCoito, I., \& Richardson, T. (2018). Teachers and technology: Present practice and future directions. Contemporary Issues in Technology and Teacher Education, 18(2), 362-378.

Gilbert, B. (2015). Online Learning Revealing the Benefits and Challenges. Online Master dissertation. School of Education. St. John Fisher College.

Hairum, N. (2020, April Carian 'Google Classroom' Di Malaysia Tertinggi Di Dunia. Sinar Harian. Retrieved https://www.sinarharian.com.my/article/79328/BERITA/Nasional/Carian-Google-Classroomdi-Malaysia-tertinggi-di-dunia.

Harjanto, A. S. \& Sumarni, S. (2019). Teachers' experiences on the use of Google Classroom. 3rd English Language and Literature International Conference (ELLiC) Proceedings, Vol 3. eISSN: 2579-7263

Heggart, K. R., \& Yoo, J. (2018). Getting the Most from Google Classroom: A Pedagogical Framework for Tertiary Educators. Australian Journal of Teacher Education, 43(3), 140-153.

Iftakhar, S (2016). Google Classroom: What Works and How? Journal of Education and Social Sciences, 3(Feb.), 12-18,

Islam, M. S., \& Ferdousi, S. A. (2019). Techno-Aide Google Classroom for Learning English: Prospects \& Challenges. Journal on Today's Ideas-Tomorrow's Technologies, 7(2), 106-117.

Lai, P. C. (2017). The literature review of technology adoption models and theories for the novelty technology. JISTEM-Journal of Information Systems and Technology Management, 14(1), 21-38.

Lee, J. (2010). Online support service quality, online learning acceptance, and student satisfaction. The Internet and Higher Education, 13(4), 277-283.

Marton, F. (1986). Phenomenography-A Research Approach to Investigating Different Understandings of Reality. Journal of Thought, 21(3), 28-49.

Basher, S. A. O. (2017). The impact of Google classroom application on the teaching efficiency of preteachers. University of Shagra-Department of Educational Sciences, 1(1), 45-55.

Sharanee, I.N.M., Mohd Jamil. J., \& Mohamad Rodzi, S.S. (2018). The Application of Google Classroom as a Tool for Teaching and Learning. Journal of Telecommunication, Electronic and Computer Engineering, 8(10), 1-7.

Sidhu, G.K., Yean, L.F.Y., Jean, L.H., \& Abdelhai, A.E. (2019). Knowledge and understanding of google classroom as a teaching and learning tool: A case study. International Journal of Advanced Science and Technology, 8(8), 687-695.

Solihati, N. and Mulyono, H. (2017). A Hybrid Classroom Instruction in Second Language Teacher Education (SLTE): A Critical Reflection of Teacher Educators. International Journal of Emerging Technologies in Learning, 12(5), 169-180.

Venkatesh, V. (2000). Determinants of Perceived Ease of Use: Integrating Control, Intrinsic Motivation, and Emotion into the Technology Acceptance Model. Information Systems Research, 11(4), 342-365.

Woldeab, D., Yawson, R. M., \& Osafo, E. (2020). A Systematic Meta-Analytic Review of Thinking beyond the Comparison of Online Versus Traditional Learning. e-Journal of Business Education \& Scholarship of Teaching, 14(1), 1-24.

Xiung, J. (2020, Jun 16). Education Ministry relaunches digital learning platform with help from Apple, Google and Microsoft. Malay Mail. Retrieved from https://www.malaymail.com/news/malaysia/2020/06/16/education-ministry-relaunchesdigital-learning-platform-with-help-from-appl/1875981.

Yang Y.F. \& Tsai C.C. (2009). Conceptions and approaches to learning through online peer assessment. Learning and Instruction, 20, 72-83.

Zakaria, M., Bustaman, H. A., Abd Manaf, K. \& Abdul Rahman, R. (2020). Exploring Benefits and Challenges of Adopting Google Classroom in Perspective of Higher Institution's Learners. Test Engineering \& Management, 9739-9749. 